\title{
An Interesting Case of Bilateral Upper Limb Wasting: Hirayama Disease
}

\author{
Priscilla Rubavathy Eugin ${ }^{1} \quad$ Manokaran Chinnusamy ${ }^{1}$ Sathiyanarayanan Janakiraman ${ }^{1}$ \\ ${ }^{1}$ Department of General Medicine, Sri Manakula Vinayagar Medical \\ College and Hospital, Pondicherry, India

\begin{abstract}
Address for correspondence Manokaran Chinnusamy, MBBS, MD, Department of General Medicine, 9, Associate Professor Quarters, Sri Manakula Vinayagar Medical College and Hospital Campus, Kalitheerthalkuppam, Madagadipet, Pondicherry 605107, India
\end{abstract} \\ (e-mail: manokaran.smvmch@gmail.com).
}

J Health Allied Sci Nu:2021;11:40-43

\begin{abstract}
Keywords

- Hirayama disease

- dynamic MRI

- motor neuron disease

Hirayama disease is a rare neurologic disease and is characterized by insidious unilateral or bilateral muscular atrophy and weakness of the forearms and hands without sensory or pyramidal signs. Our patient presented with bilateral upper limb wasting, which is a rarer variant of motor neuron disease. The diagnosis of Hirayama disease is based on dynamic magnetic resonance imaging (MRI). This case displays how dynamic cervical spine MRI can pick up dynamic cord compression and contributes to zero in the diagnosis of Hirayama disease.
\end{abstract}

\section{Introduction}

Hirayama disease is a rare neurological disease and is characterized by insidious unilateral or bilateral muscular atrophy and weakness of the forearms and hands without sensory or pyramidal signs. The disease primarily affects men in the second or third decades of life. The disease progresses initially, but spontaneous arrest is known to follow several years after the onset.

\section{Case Report}

\section{History and Examination}

A 20-year-old male presented with complaints of insidious onset symmetric weakness of hands due to lifting heavy objects for 7 months. It progressed to reduced dexterity, with difficulty in mixing food, buttoning of clothes, and combing hair. Furthermore, he noted wasting of muscles and clawing of fingers for last the 4 months ( $\mathbf{- F i g . ~ 1 )}$ ). There was no history suggestive of involvement of higher mental function, cranial nerves, lower limbs, bowel and bladder, or sensory system. There were also no other known comorbidities.

On examination, the patient had weakness involving both hands, with a handgrip of $60 \%$ and impaired abduction and adduction of the digits and opposition of the thumb, with wasting and fasciculation. All other reflexes were normal. Powers of arm and forearm muscles were normal. Sensations were intact. There was no evidence of involvement of the pyramidal, spinothalamic, posterior column lesions, polyminimyoclonus, or autonomic disturbances. The patient was provisionally diagnosed with bilateral upper limb distal wasting under evaluation, and work-up for cervical spine pathology, predominant motor neuropathy, and distal myopathy was considered along with possibility of motor neuron disease (MND) variant.

\section{Investigation}

- Blood investigations such as complete blood count, sedimentation rate, and renal, liver, and thyroid function tests were within normal limits, including creatine phosphokinase levels.

- Magnetic resonance imaging (MRI) cervical spine: loss of cervical lordosis. In the neutral position, there is asymmetrical focal cervical cord flattening noted from C5-C7. On flexion MRI, there is anterior displacement of the cervical cord, with cord and spinal canal compression noted from C5 to C7 level ( - Fig. 2). Anterior shift of the posterior dura with T2-weighted image (T2WI) and short tau inversion recovery (STIR) ( - Fig. 3 ) hyperintense collection is noted in the epidural space for an approximate length of $12 \mathrm{~cm}$ with a maximum thickness of $8 \mathrm{~mm}$ with few curvilinear large T2WI flow voids noted within, representing epidural venous engorgement ( - Fig. 4). published online

October 16, 2020
DOI https://doi.org/

10.1055/s-0040-1718237

ISSN 2582-4287. (c) 2020. Nitte (Deemed to be University).

This is an open access article published by Thieme under the terms of the Creative Commons Attribution-NonDerivative-NonCommercial-License, permitting copying and reproduction so long as the original work is given appropriate credit. Contents may not be used for commercial purposes, or adapted, remixed, transformed or built upon. (https://creativecommons.org/licenses/by-nc-nd/4.0/).

Thieme Medical and Scientific Publishers Pvt. Ltd. A-12, 2nd Floor, Sector 2, Noida-201301 UP, India 

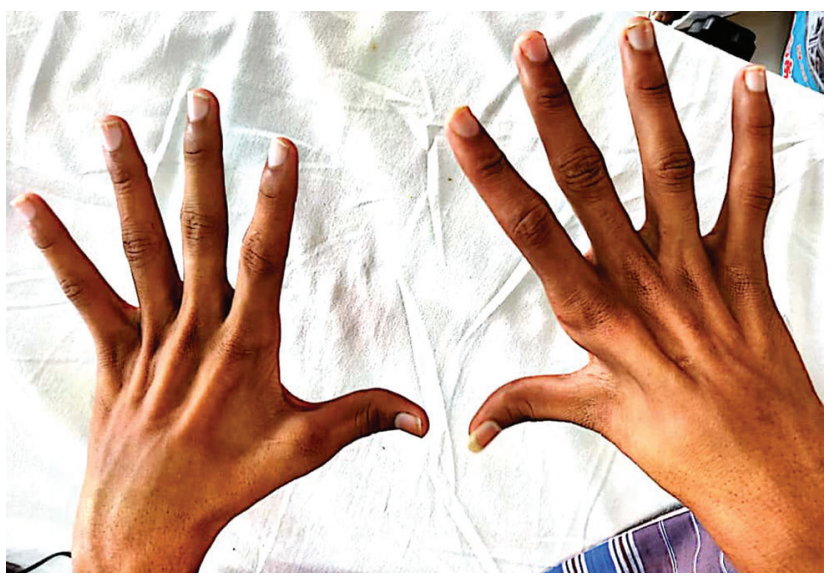

Fig. 1 Hollowing of intertendinous spaces and clawing of hands.

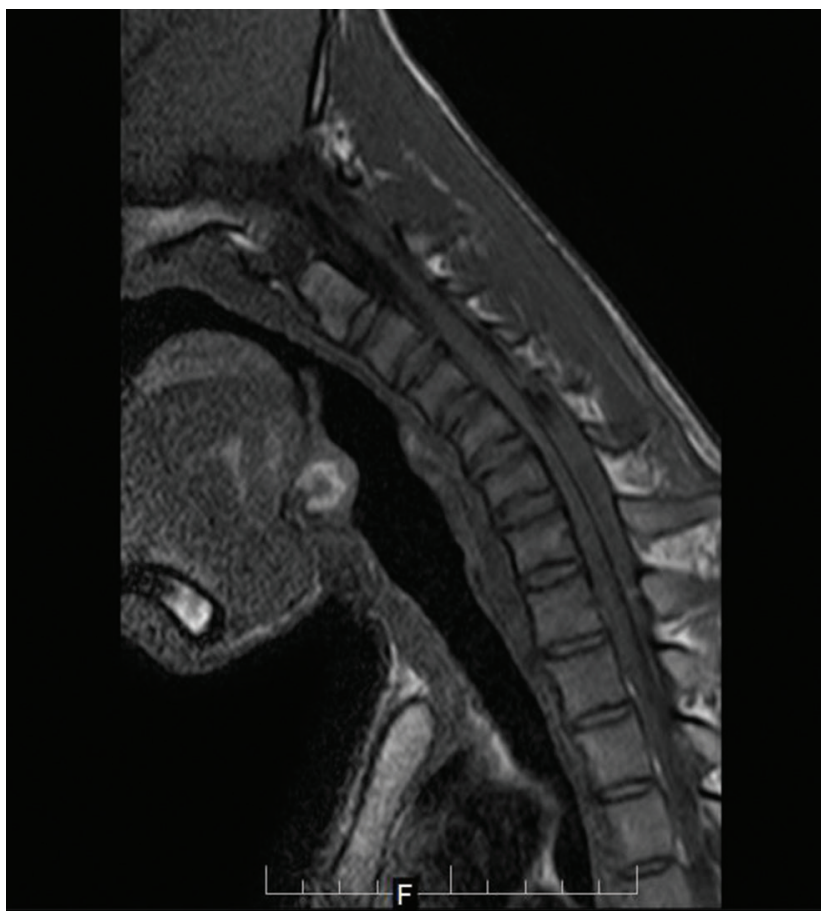

Fig. 2 T1-weighted image showing anterior displacement of the cervical cord with cord and spinal canal compression noted from C5 to $C 7$ level.

- CPK levels: $15 \mathrm{IU} / \mathrm{L}$.

- Nerve conduction study: decreased compound motor action potential amplitude in the right median nerve

- Possibility of multiple mononeuropathy (amplitude may decrease because of atrophic muscles; hence, the test was limited to this nerve, and the other limb was not further tested).

- Needle electromyography (EMG): no spontaneous activity, large motor unit action potential, no polyphasia, discrete interference pattern favors neurogenic EMG pattern ( - Fig. 5).

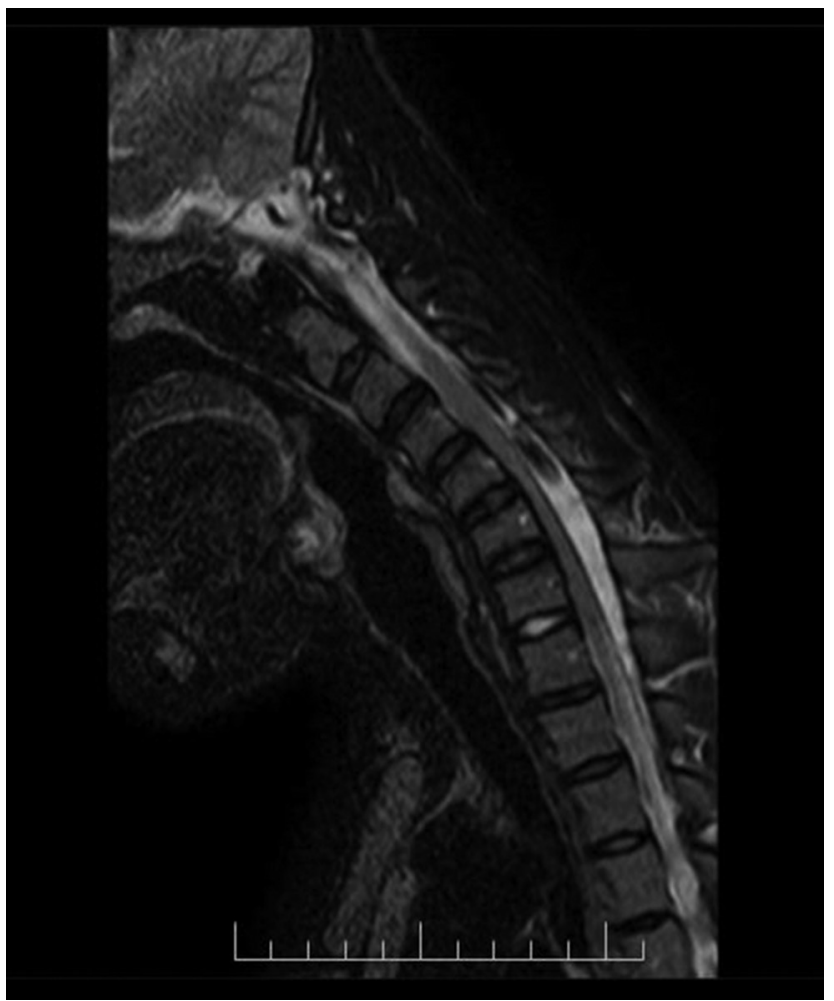

Fig. 3 STIR (short tau inversion recovery) image: hyperintense collection noted in the epidural space for an approximate length of $12 \mathrm{~cm}$ with a maximum thickness of $8 \mathrm{~mm}$.

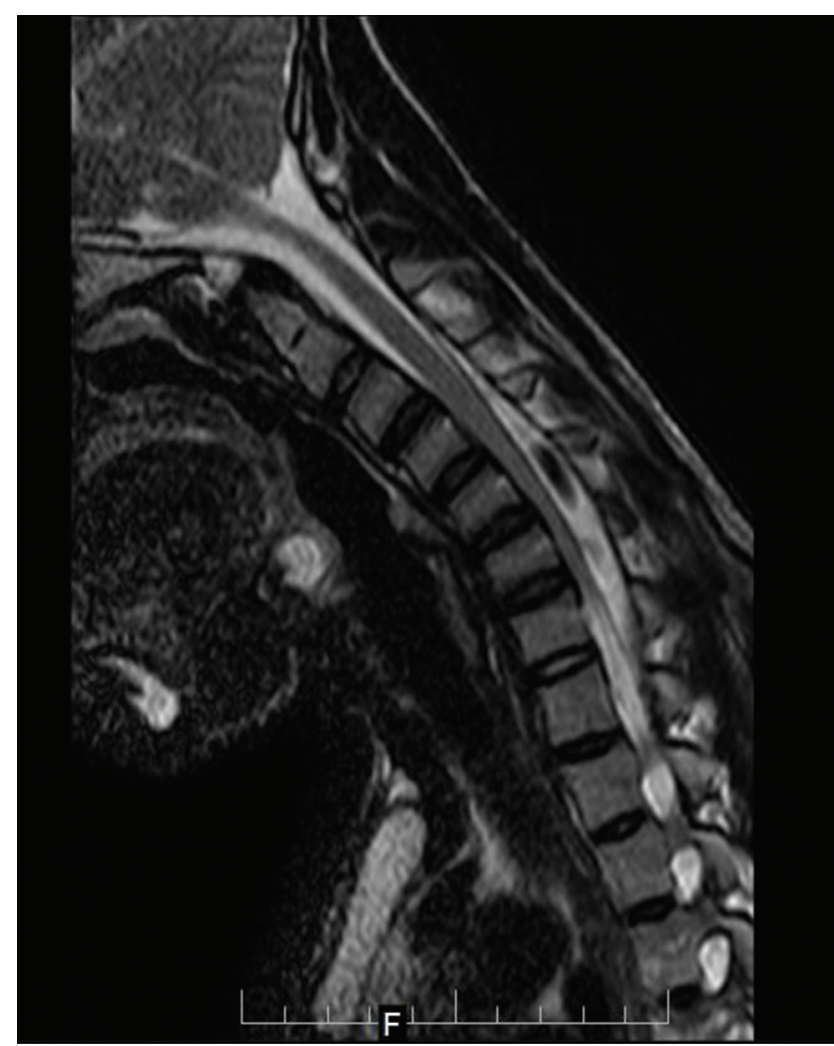

Fig. 4 T2-weighted image (T2WI): anterior shift of the posterior dura noted with few curvilinear large T2WI flow voids noted within, representing epidural venous engorgement. 


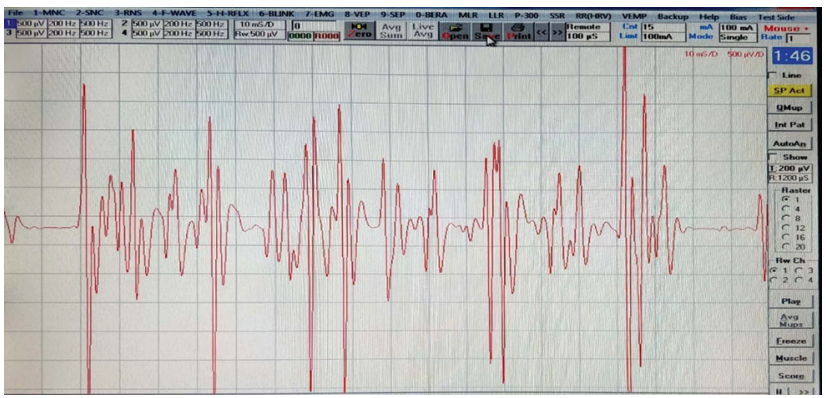

Fig. 5 Needle electromyography: large motor unit action potential.

\section{Discussion}

Hirayama et al from Japan reported atrophy of a single upper limb and labeled it as "juvenile muscular atrophy of unilateral upper extremity."1 Most of the cases have been reported from Japan and India, as well as other Asian countries. Insidious onset of atrophy and weakness, presumed to be due to anterior horn cell involvement, starting in the second or third decade of life with male preponderance and sporadic occurrence are the characteristic features. ${ }^{2}$ Progression is slow and followed by stabilization within a few years, resulting in a benign outcome. Cranial, pyramidal, sensory, cerebellar, and extrapyramidal systems are not involved. ${ }^{3}$ The most common pattern is unilateral atrophy of C7-T1 innervated muscles, with sparing of the brachioradialis ("oblique atrophy" pattern). Spread may occur to the contralateral limb in approximately $20 \%$ of cases and rarely patients later develop an ALS (amyotrophic lateral sclerosis)-like picture. ${ }^{4}$

The most prevalent pathophysiology of Hirayama disease is that wasting and weakness associated with this disease is because of imbalanced growth between the patient's vertebral column and spinal canal contents. This imbalanced growth leads to a tight dural sac, which displaces the posterior dural wall anteriorly when the neck is flexed. ${ }^{5}$ The dura is unable to compensate for increase in the posterior wall of the cervical spine on neck flexion. This causes the posterior dural wall to shift anteriorly, causing compression of the cervical spinal cord against the vertebral bodies. The spinal artery is compressed, which leads to microcirculatory disturbances, which affect the anterior horn cells, resulting in localized cord atrophy in the lower cervical cord. ${ }^{6,7}$

However, surgical decompression has not altered the course of the disease, and this theory is no longer widely held. Another school of thought is that this is a segmental, perhaps genetically determined, spinal muscular atrophy, but the actual cause is still unknown.

In an article published by Tashiro et $\mathrm{al}^{8}{ }^{8}$ the requirements for the diagnosis of Hirayama disease are as follows:

- Distal weakness and muscular atrophy mainly involving the forearm and hand.

- Predominantly involves the unilateral upper extremity.

- Onset usually at the age of 10 to 20 years.
- Insidious onset with gradual progression for the first few years followed by stabilization;

- No involvement of the lower limbs.

- No sensory disturbance and tendon reflex abnormalities.

The key investigation could be MRI cervical spine images with neck flexion. It shows the anterior displacement of the posterior wall and a well-enhanced crescent-shaped lesion in the posterior epidural space of the lower cervical canal. This lesion is thought to represent congestion of the posterior internal vertebral venous plexus.

The key diagnostic features as suggested by Chen et $\mathrm{al}^{9}{ }^{9}$ which are helpful in the radiological diagnosis of Hirayama disease are as follows:

- Localized cervical cord atrophy

- Abnormal cervical curvature

- Asymmetric cord flattening with parenchymal changes in the lower cervical cord

- Loss of attachment between the posterior dural sac and adjacent lamina

- Anterior shifting of the posterior wall of the cervical dural canal

- Enhancing epidural component in the lower cervical and thoracic region

- Prominent epidural flow voids suggestive of dilated venous plexus

Although Hirayama disease is a self-limiting disorder, early diagnosis is necessary because a cervical collar, by preventing neck flexion, may arrest the progression of the disorder. Conservative treatment using a cervical collar for a duration of 3 to 4 years should be given if helpful in majority of the cases. ${ }^{10}$ Muscle-strengthening exercises and practices for the coordination of hand movements are also very useful. Vertebral fusion surgery is reserved for advanced cases with persistent neurologic deficit and clinical deterioration despite a correct conservative therapy.

\section{Conclusion}

This case displays how dynamic cervical spine MRI can pick up dynamic cord compression and contributes to zero in the diagnosis of Hirayama disease. Our patient presented with bilateral upper limb distal wasting was found to have clinicoradiological features favoring Hirayama disease, which itself is a rare MND variant, and bilateral involvement like in this case is even rarer.

\section{Conflict of Interest}

None declared.

\section{Acknowledgment}

The authors extend sincere thanks to Dr. Ashish Anand Susvirkar, Assistant Professor, Department of Neurology, Sri Manakula Vinayagar Medical College and Hospital, for his help and guidance in managing this case. 


\section{References}

1 Hirayama K, Toyokura Y, Tsubaki T. Juvenile muscular atrophy of unilateral upper extremity: a new clinical entity. J Psychiatr Neurol. 1959;61:2190-2197

2 Hirayama K, Tomonaga M, Kitano K, Yamada T, Kojima S, Arai K. Focal cervical poliopathy causing juvenile muscular atrophy of distal upper extremity: a pathological study. J Neurol Neurosurg Psychiatry 1987;50(3):285-290

3 Pal PK, Atchayaram N, Goel G, Beulah E. Central motor conduction in brachial monomelic amyotrophy. Neurol India 2008;56(4):438-443

4 Lewis D, Saxena A, Herwadkar A, Leach J. A confirmed case in the United Kingdom of Hirayama disease in a young white male presenting with hand weakness. World Neurosurg 2017;105:1039.e7-1039.e12

5 Pradhan S, Gupta RK. Magnetic resonance imaging in juvenile asymmetric segmental spinal muscular atrophy. J Neurol Sci 1997;146(2):133-138
6 Hirayama K, Non-progressive juvenile spinal muscular atrophy of the distal upper limb (Hirayama's disease) In: De Jong JM, ed. Handbook of Clinical Neurology. Vol. 15. Amsterdam: Elsevier; 1991 107-120

7 Toma S, Shiozawa Z. Amyotrophic cervical myelopathy in adolescence. J Neurol Neurosurg Psychiatry 1995;58(1):56-64

8 Tashiro K, Kikuchi S, Itoyama Y, et al. Nationwide survey of juvenile muscular atrophy of distal upper extremity (Hirayama disease) in Japan. Amyotroph Lateral Scler 2006;7(1):38-45

9 Chen CJ, Chen CM, Wu CL, Ro LS, Chen ST, Lee TH. Hirayama disease: MR diagnosis. AJNRAmJNeuroradiol 1998;19(2):365-368

10 Tokumaru Y, Hirayama K. Cervical collar therapy for juvenile muscular atrophy of distal upper extremity (Hirayama disease): results from 38 cases [in Japanese]. Rinsho Shinkeigaku 2001;41(4-5):173-178 